\section{The INCITE model of policy development for the creative industries: the case of Vietnam}

The INCITE model of policy development

\author{
Marta Gasparin and Martin Quinn \\ University of Leicester, Leicester, UK
}

\begin{abstract}
Purpose - This paper develops a new model of policy development for the creative industries in a transitional economy setting. These sectors could potentially make a significant contribution to the continuing growth of the Vietnamese economy; however, they are currently held back by a lack of policies designed to support them Design/methodology/approach - The paper uses data collected from a mixed-methods study of the creative and cultural sectors in Vietnam. The paper combines quantitative results from a mapping project with ethnographic observations and several qualitative interviews to identify the policy needs of the sector.

Findings - The paper develops the INCITE model of policy development composed of four parts: education and human resources, infrastructure, intellectual property rights and freedom of speech.

Originality/value - The paper contributes to our understanding of the kinds of policies needed to support the creative industries by exploring their development in an economy transitioning from a state planned economy to a market-driven one.
\end{abstract}

Keywords Creative industries, Policy development, Transitional economies, Vietnam

Paper type Research paper

\section{Introduction}

Vietnam's National Strategy for the Cultural Industries, ratified in 2016, sets out a series of ambitious economic targets for the creative economies to increase their contribution to the nation's overall economic performance by 2030. This is understandable as numerous scholars (see, for example; Jones et al., 2004, Markusen, 2006, Potts and Cunningham, 2008, Florida, 2002, 2014, Mellander et al., 2013) have demonstrated that the creative industries have a major economic impact on a nation's economy. This is as true in developing and transitional economies as it is in developed economies (UNESCO, 2015). Recent research by Gasparin et al. (2020) has shown that the cultural and creative industries can create several different kinds of value (economic, social and cultural) within a society and its economy. However, in order for this value to be fully realised, a policy framework that recognises the unique challenges faced by creative businesses needs to be put in place.

This article is supportive of the drive to incorporate the creative and cultural industries into Vietnam's economic planning. It argues that, in order to achieve the targets being set, there is a pressing need to design policies that are based on a firm understanding of the issues facing the creative industries in Vietnam. In order to fully realise the potential of creative industries, policies relevant to the sector in Vietnam need to be implemented. The research presented in this article seeks to identify the needs and requirements of the sector and then propose a model of policy development to support the Vietnamese creative industries.

\section{JEL Classification - O38, L53, Z18}

(C) Marta Gasparin and Martin Quinn. Published in Journal of Asian Business and Economic Studies. Published by Emerald Publishing Limited. This article is published under the Creative Commons Attribution (CCBY 4.0) licence. Anyone may reproduce, distribute, translate and create derivative works of this article (for both commercial and non-commercial purposes), subject to full attribution to the original publication and authors. The full terms of this licence may be seen at http://creativecommons. org/licences/by/4.0/legalcode

The research in the paper was funded by a grant from the British Council
Received 23 December 2019 Revised 27 February 2020 Accepted 7 April 2020

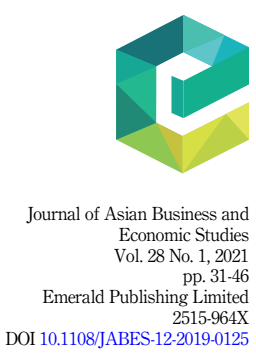


JABES 28,1

Examples of policies designed for the creative industries are commonplace across the development world (Mellander et al., 2013). It is increasingly tempting for governments to simply pick a successful policy intervention from one place and "transfer" it to a new setting (Peck, 2011; Cairney, 2015). However, as Cairney (2015) demonstrates, the policy process includes a number of steps that need to be taken to produce effective, workable policies. An integral part of the process is agenda-setting, and policy formulation which must come before strategies and targets can be set and implemented. Cairney's policy cycle includes numerous points at which the various stakeholders within an area of policy (communities, businesses, politicians) can interact and feed into the development of policy. Missing steps in the policy process weaken the understanding of the context that De Beukelaer (2014) argues is vital in creating good policy, and as Peck (2011) has shown, there are significant pitfalls in assuming policy solutions or targets can simply be transferred from one setting to another. The policy transfer process tends to ignore the specifics of the place or sector to which the policy is being moved.

Vietnam's National Strategy for the Cultural Industries was ratified before a clear understanding of the needs of the sector in Vietnam was established, and as the government has acknowledged, there is a practical information gap in the policy process. This needs to be filled with evidence from key stakeholders in the creative industry to check if the targets are feasible and to establish what policies are required to help meet those targets. Our paper draws from research carried out in Vietnam to address this gap, by providing the evidence base from which to identify the policy priorities emerging from within the creative industries. Our study over two years involved a three-stage methodology, including desk research to establish what was already known of the creative industries in Vietnam, a quantitative survey of the sectors in Hanoi and Ho Chi Minh City and an in-depth qualitative data collection and analysis.

The paper makes three contributions to the broader evidence base of policy needs of the creative industries.

(1) Theoretically, we advance the theory by proposing a policy development model in the creative industries by constructing the "INCITE Model" (Innovation and Creativity in Transitional Economies) for the creative industries in a transitional economy which acts as the building blocks for the development of the sector. We enhance the research in policy studies on the need for policymakers to understand a context before deciding on policy interventions.

(2) Empirically, we extend the debate on policy development in the cultural industries through the presentation of original data from one of the few remaining communist countries in the world, which is currently under-researched.

The paper proceeds as follows. First, we briefly discuss some of the key literature on the creative industries and the creative economy. Secondly, we outline the context within which the creative sectors operate in Vietnam, and we discuss some of the findings of the desk-research stage. We then briefly explain our methodology before outlining our model of policy development needed to allow the creative sector in Vietnam to thrive.

\section{Creative economies}

An increasing number of countries across the globe are attempting to use the arts, cultural and creative industries as drivers of economic development. Policymakers are increasingly viewing culture (Florida, 2002) as a panacea for modern urban development. Using a series of case studies on the impact of arts and culture on the economic and social life of large mega cities, Florida (2002) developed a blueprint that smaller cities can follow to be attractive and competitive in the race of attracting inward investments, talents and tourists. Florida (2014) 
argues that the best way to develop local economies is to attract the creative and cultural class. States and cities across the world have adopted his ideas. It is possible to see notable investments on infrastructures and projects following Florida's principle. However, some researchers have raised doubts about the viability of this model (Peck, 2005). Building on this, Mellander et al. (2013) suggest that if there are creative areas in a city, which are vibrant and offering the possibility of enjoying life after work, the creative class might start using them and eventually decide to move there. In fact, the creative class values both the economic and lifestyle considerations; places that are innovative, diverse and tolerant are more attractive (Florida, 2002, 2014).

The creative class, broadly speaking, engages in work the function of which is to "create meaningful new forms", and includes scientists and engineers, university professors, poets and novelists, artists, entertainers, actors, designers and architects, nonfiction writers, editors, cultural figures, think-tank researchers, analysts and other opinion-makers (Florida, 2002). These members have a high salary, and they produce goods that contribute not only to the overall GDP with their services, but are also generating work for "creative professionals". Creative professionals are workers within a wide range of knowledge-based occupations in high-tech sectors, financial industry, the legal and healthcare and business management (Florida, 2014). These professionals engage in creative problem-solving, have a high degree of formal education and of human capital and do not mind travelling from a city to another (Mellander et al., 2013).

Florida's (2002) work on the creative class also encourages the promotion of the 3Ts (technology, tolerance and talent) as essential components in a city and community to support the development of a "creative class". The creative economy can become a key determinant of economic growth and prosperity as culture can be used instrumentally to develop urban economies (O'Brien, 2013). Policymakers can mobilise cultural values as assets and sources of vitality to renew economic and social spaces. This precept has been adopted, largely uncritically, as a model of urban development in the Global North (Mellander et al.,2013). Major manifestations of such a use of culture are exemplified in the UK and EU cities of culture competitions. On a more micro level, it has been used to construct "cultural quarters", heritage focused re-developments and the urban planning of creative industries (Quinn and Courtney, 2016).

On the one hand, these trends signify that the culture is managed, maintained and manipulated by and for economic and political interests, rather than being a vernacular reflection of people's ways of life as it is in its folk origins (Quinn and Courtney, 2016). On the other hand, research on the creative industries conducted in Europe and North America highlights that creative organisations favour an entrepreneurial ecosystem, defined as the social and economic environment affecting local/regional entrepreneurship (Pratt, 2014; Mc Robbie, 2016). Here, creative hubs and cultural quarters are regarded as a fulcrum of the growth of the knowledge economy (Evans, 2009; McKinlay and Smith, 2009) as they act as knowledge brokers facilitating knowledge transfer (Mc Robbie, 2016) by brokering not only ideas, but also dynamically bringing together different talents, skills and disciplines and consequently positively impacting on innovation rate (Clement et al., 2018). They also contribute to human resource development by organising informal education (Davies and Sigthorsson, 2013; Gasparin et al., 2020). Because they become centres for new innovative products/services based on creativity and talent, they tend to stimulate future public and commercial investment (Evans, 2009). In terms of urban development, these sectors create positive engagement with the public, who then consume innovative, cultural and creative products (O'Brien, 2013), stimulating a virtuous cycle: increasing the demand for creative activities will further stimulate demand in current consumers and attract neighbouring communities to visit. This spending will enhance community wealth, and hence provide the resources for urban regeneration and economic development (Florida, 2014).
The INCITE model of policy development

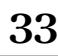


JABES

28,1

\section{4}

Table 1.

Vietnamese government statistics office data on the creative industries 2015

\section{Vietnamese context}

Vietnam as a nation is relatively young, but it has a long, shared history and a rich, diverse, cultural heritage, which starts to be integrated and complemented within new creative and innovative activities. During this research, we noted that culture, heritage and creativity are not treated yet as asset, neither from a cultural nor from an economic dimension. In fact, heritage could be mobilised and connected to the different ethnic communities, rediscover their identity and link them together, combining the rich cultural and creative past in the present and connecting it with the future. Vietnamese heritage and culture are complex; Vietnam has 54 ethnic minorities, all with their traditions, culture and heritage.

In fact, cultural heritage can become the driver of the territorial development, identity and value creation (Markusen, 2006), but currently in Vietnam, it is not well developed and preserved. There are few rules and roles established to create a cultural heritage. Moreover, cultural heritage is not properly and extensively considered an actor to be used to create values, as only few infrastructures are in place. Links between cultural heritage and touristic industry are emerging. As discussed in the literature review, cultural heritage and creative economy can be drivers for urban regeneration (Florida, 2002; Mellander et al., 2013), and they can also create a sense of belonging to the population.

The creative industries are an emerging force in Vietnam's rapidly developing economy. Based on government figures, we have estimated that as of 2015, at least 3.8 million people (see Table 1) are employed in the creative and cultural industries, which is approximately $5.7 \%$ of the active workforce in Vietnam. However, these figures tend to underestimate the full extent of private sector enterprise which is under-represented in official statistics, as the transition from a state-planned to a market-driven economy occurs at a pace that dovernment officials have struggled to keep up with. The Vietnamese creative economy has the potential to become one of the driving forces for changes and economic development in Vietnam (World Bank Group and Ministry of Planning and Investment of Vietnam, 2016). This unique sector brings together the old and the new in the Vietnamese economy, with innovation and creative economies supplementing the traditional manufacturing industries to create something truly "Vietnamese".

The data in the Table 1 are taken from the Vietnamese Government Statistics Office and show that the cultural and creative industries play a significant role in the Vietnamese economy. The sector overall contributed at least 1,298,545 bn Vietnamese dong/US $\$ 56$ bn per

\begin{tabular}{lrccr}
\hline & Number of & $\begin{array}{c}\text { Average revenue per } \\
\text { company } \\
\text { (billion dong) }\end{array}$ & $\begin{array}{c}\text { Total revenue for the } \\
\text { sub-sector } \\
\text { (billion dong) }\end{array}$ & $\begin{array}{c}\text { Total employment } \\
\text { in sub-sector }\end{array}$ \\
Sub-sector & companies & 6.50 & 55,597 & 71,480 \\
Advertising & 8,543 & 4.29 & 76,117 & 225,855 \\
Architecture & 17,739 & 4.50 & 8,152 & 51,060 \\
Interior design & 1811 & 41.66 & 153,185 & 339,695 \\
Art and antiques & 3,677 & 20.85 & 90,323 & 126,375 \\
Crafts & 4,332 & 8.23 & 42,639 & 72,034 \\
Design companies & 5,183 & 71.59 & 748,392 & $2,721,354$ \\
Fashion design & 10,454 & 13.62 & 13,890 & 15,473 \\
Film and video & 1,020 & 8.52 & 48,818 & 89,462 \\
Software etc & 5,733 & 107.97 & 9,609 & 8,289 \\
TV and radio & 89 & 5.82 & 13,419 & 40,336 \\
Performing arts, & 2,304 & 7.28 & 5,68 & 9,687 \\
entertainment & 809 & 6.66 & 32,515 & 35,136 \\
Publishing & 4,879 & 19.50 & $1,298,545$ & $3,806,236$ \\
Tourism & 66,573 & & &
\end{tabular}


year as of 2015, with an average revenue of around 19.5 bn dong/ US\$841,756 per company, although it should be noted that this figure is significantly skewed by TV \& radio (average 107.97 billion dong/ US $\$ 4.6$ million USD), fashion design (71.59 billion dong/ US $\$ 3$ million) and arts \& antiques (41.66 billion dong/ US\$1.8 million USD), with all other sectors being below average for revenue. For employment, the data suggest at least 3.8 million people are employed in the cultural and creative industries in Vietnam - by far the largest sector according to the government data is fashion design, which accounted for more than 2.7 million of the overall total. Another note on the data is that the year-on-year figures for most sub-sectors increased markedly in the government data sets (advertising and architecture both doubled in size between 2011 and 2015, for example). This might suggest that not only the sector is developing, but also the data collection might have improved, as well as the coverage of the sectors. Thus, the following figures should be treated as a minimum indicator of the size and scope of the cultural and creative industries in Vietnam.

Whilst the creative economy and the cultural activities have a lot of potential, they are facing several struggles, which have been identified by analysing the interviews and were confirmed by the survey: (1) Clear definition of the sector, (2) a lack of education regarding intellectual property and enforcement of IP protection, (3) a lack of a creative and innovative eco-system, (4) a lack of creativity and innovation management education, (5) a lack of innovative business models suitable for the creative sector, (6) poor education and interest of end users, (7) difficulties in accessing finances, (8)strong self-censorship due to the presence of censorship and (9) challenging regulatory systems. These struggles are then manifested in a widespread (10) lack of adoption and implementation of digital technologies and (11) a difficulty in identifying and implementing business models that could support organisational growth. In fact, innovators and creative people find it difficult to innovate the business models. This is due not only to a lack of the necessary knowledge on management principles, but also because they are not encouraged to explore innovative possibilities: they feel constrained by rigid regulations that do not take into consideration the complexities of the creative industries. The presence of regulations (frequently considered unclear, unfitted and always changing) also creates distrust, and this discourages organisations from making long-term investments and strategic plans for growth, resulting in short-term goals aimed at survival. On many fronts, creativity continues to evolve rapidly and radically, guaranteeing opportunities for innovators, although the Vietnamese government is not ready to fully embrace the inevitable ambiguity that comes with new technologies. Big data, the Internet of things, wearable computers, assisted creativity and the maker movement provide examples of this continued dynamics in other countries, which are not fully supported and therefore not yet developed in Vietnam.

In 2016, Vietnam's Ministry of Planning and the World Bank published Vietnam 2035: Toward Prosperity, Creativity, Equity and Democracy, which states:

In the long term, countries with more open and inclusive political institutions generate greater room for innovation and personal creativity, thus stimulating productivity improvements and higher standards of living. For Vietnam, finding ways of building more open and accountable political institutions will eventually be essential.

Thus, stakeholders and policymakers need to develop policies to preserve this heritage and at the same time encourage organisations to engage with innovative new cultural content. In the recent years, there have been some developments within the policy framework. The general objectives of the Resolution no. 102/NQ-CP dated 31 December 2014 of the government promulgating the government's action programme to implement the Resolution No. 33-NQ/ TW dated 09 June 2014 of the 9th Plenum of the 11th Central Committee of the Communist Party of Vietnam on constructing and developing Vietnamese culture and peoples to meet the requirements of sustainably developing the country aims to:
The INCITE model of policy development 
JABES

28,1

\section{6}

(1) develop the Vietnamese cultural industries, including advertising; architecture; software and entertaining games; handicrafts; designing; cinema; publishing; fashion; performing arts; fine arts, photography and exhibitions; television and radio and cultural tourism into important economic and service sectors, gaining remarkable developments in quantity and quality;

(2) contribute positively to economic growth and job creation through producing more cultural products and services with great diversity and high quality, satisfying the needs of innovation, enjoyment and cultural consumption of the people in the country and for exporting purposes;

(3) contribute to the promotion of the images of the country and people of Vietnam, establishing the trademarks of cultural products and services and giving development priorities to sectors with advantages and potentials of Vietnam;

(4) develop external relations and cross-sector interaction in order to present an integrated offer (e.g. Department of Tourism could work with Performing Arts to prepare a strategy for cultural tourism, or with Film Ministry to develop offers that go through the movie locations);

(5) implement the UNESCO Convention on the Protection and Promotion of the Diversity of Cultural Expressions, which illustrates the new role of cultural diversity at international level. This will roll out to implement also UN Sustainable Development Goals as parties, the community and its member states have committed themselves to strengthen a new cultural pillar of global governance and sustainable development, notably through enhancing international cooperation.

The Vietnam National Institute for Culture and Arts Studies (VICAS), the Vietnam Rural Industries Research and Development Institute (VIRI) and overseas agencies, like the British Council, are active and successfully addressing some of the challenges faced by the creative sector. However, it requires a more integrated and systematic offer to address the challenges. VICAS has contributed to the writing of 2014 National Strategy, providing inputs and information, supported by the British Council. Following this strategy, the Department of Copyright, which belongs to the Ministry of Culture, Sport and Tourism, has started a mapping at the macro level of the cultural and creativity activities, which started with two trips to the UK in 2016 to visit successful creative cases (e.g. London and Liverpool). It is currently working on a framework, meeting with the various ministers to develop a national implementation strategy.

The SME department is developing a policy to support the innovative enterprise and new models to start new businesses, since it is aware that current regulations are constraining the development of the creative industries. At the time of the interview, the SME department was working with the innovative enterprises to set up and support the value chain of clusters, and it is aware of the need of changing the tax regulatory system. We also discussed the land use management - for example, how to stimulate the creation of the co-working spaces and the creation of clusters and networks of creative and innovative enterprises to support the value chain. The department is willing to explore what is of value in the cultural and creative economy, and how to integrate it in the value chain.

\section{Materials and methods}

Our paper is based on research project carried out in Vietnam. Our study followed a three-step methodology combining desk research alongside empirical quantitative and qualitative data collection. The aim of the research was to map the cultural and creative industries in Vietnam, 
and, following this, to gain a deep understanding of the needs and requirements of the sector. The desk research examined existing data sets and reports into culture and creativity in Vietnam and highlighted several gaps in the data. Therefore, we followed this up with a quantitative survey, qualitative interviews and field observations. In this paper, we present the results related to policy needs that emerged from the data.

The qualitative method adopted in this research involved an interpretive approach (Denzin and Lincoln, 2002) to understand creative industries in a transitional economy. This qualitative approach facilitates and permits context-dependent knowledge and the capture of emergent issues and does not begin with a set hypothesis. Field research was conducted for seven months: two for sensitising the researcher to the environment, and three completely immersed (July-October 2017) and two for validating the data. Within this timeframe, the visual ethnography (Pink, 2013), in-depth interviews, informal conversations and observations were conducted. Forty-three interviews were conducted with creative organisations and government ministries. Thirty-one semi-structured interviews were recorded, lasting between 42 and $85 \mathrm{~min}$. Twelve of these interviews were not recorded but notes were taken. For the policymakers section of the interviews, 11 ministerial teams participated in group interviews within which 37 individuals participated. The first author also participated in six project launches and two three-day events. The interviews were conducted in English (on three occasions, via a translator).

The survey was carried out in November 2017-May 2018 to maximise response rates as much as possible. During the desk research stage, we were able to compile a list of contacts across our target sectors of around 4,000 addresses. The vast majority of these were in either Hanoi or Ho Chi Minh City, with only handfuls in other urban areas. Responses proved difficult to get, and we engaged with local partners to boost responses by following up by emails, phone calls and by assisting responders in filling in the survey. In all, 380 unique records were created on the Qualtrics site; however, around 100 of these completed the first few questions, with the bulk of the survey being completed by 235-280 people, depending on the question; there was a low response rate of less than $10 \%$ of the original database. The survey was designed both to fill the gaps in existing statistics on the sector and to start the process of understanding the challenges facing organisations working in the sector.

\section{Developing the INCITE model of policy development to encourage growth and innovation in the creative industries}

The potential for the creative economies is enormous, but it is not considered sustainable yet; the people are there, the ideas are there, but they need to be nurtured and supported to create and develop a sustainable social economy. However, before many of the issues present can be addressed, there is a pressing need for the government to agree on a clear and common definition of the creative industries and the wider creative economy. This will have two benefits: increasing the understanding of what the industry is, and improving the quality and quantity of data being collected on it.

Thus, our research began by questioning the definition of creativity and creative economy, as each country has its own definition of the creative and cultural industries, which include sectors that are particularly relevant within the local context. It took several weeks of discussion between the UK and the Vietnamese partners to find a definition that could be used and that would make sense for the context.

In the UK, the creative and cultural industries are defined as those "industries which have their origin in individual creativity, skill and talent and which have a potential for wealth and job creation through the generation and exploitation of intellectual property" (DCMS, 2001, p. 4). UNESCO defines cultural and creative industries as "sectors of organised activity whose principal purpose is the production or reproduction, promotion, distribution and/or
The INCITE model of policy development 
JABES

28,1

38

commercialisation of goods, services and activities of a cultural, artistic or heritage-related nature". This approach emphasises more than just the industrially made products of human creativity; it makes relevant the entire productive chain, as well as the specific functions of each sector involved in bringing these creations to the public. Thus, the definition also encompasses related activities, such as publicity and graphic design, which are decisive factors in this process

However, these posed some challenges in terms of deciding what to include and what to exclude in the survey and in the qualitative research. There was also the problem of translation and use of the Western world in the Vietnamese context. For example, in the process, we have realised that there is not an exact direct Vietnamese translation for design or innovation (as it is intended in English language), which created few misinterpretations at the beginning of the research.

Therefore, we started by taking the definitions of "the creative economy" (e.g., Howkins, 2002; Adler, 2011) and "aesthetic knowledge" (Ewenstein and Whyte, 2007) to focus on sectors which are part of artistic creation, production, distribution/dissemination and consumption/experience of cultural and creative products in Vietnam. From here, we worked with our research partners in Vietnam and identified the following creative and cultural sectors as being the core of the industry in Vietnam and will be referring to sub-sectors of the creative industries throughout the following analysis:

(1) Advertising.

(2) Apps and software development.

(3) Architecture.

(4) Art and antiques market/ trade.

(5) Cinema and video.

(6) Crafts.

(7) Fashion design and jewellery.

(8) Galleries and exhibitions.

(9) Graphic design.

(10) Gastronomy.

(11) Hubs (creative, innovation, technology and co-working spaces).

(12) Interior design.

(13) Music.

(14) Paintings, sculpture, drawings and prints.

(15) Performing arts.

(16) Photography, visual arts.

(17) Publishing.

(18) Radio.

(19) Television.

(20) Tourism. 
In the survey, respondents were asked to consider different business needs and rate them in terms of challenges. As seen from Table 2, access to finance was rated as a significant challenge by around a third of respondents and had the lowest overall average in the table. Skills shortage, getting the right staff and finding a location to start a business were other challenges. Interestingly, it can be inferred from the figures that finding the right location for a business becomes easier once businesses move beyond the start-up phase, as finding the right location and land issues were not seen as big a challenge as finding a place to start a business.

Interestingly, once respondents were asked to identify the biggest challenge from the same list, "getting the right staff" overtook "access to finance" as the most common answer (Table 3), with one-third saying staffing was their biggest challenge compared to a little over a fifth for finance. Skills shortages completed the top three choices. It is common for staff and skills shortages to feature together in human resource surveys and is something for
The INCITE model of policy development

Table 2 .

To what extent are the following issues a challenge for your business: (rank 1-5: 1 is a significant challenge, and 5 not a challenge) $\%$

\begin{tabular}{lr}
\hline Challenge & $\%$ \\
\hline Getting the right staff & 34.5 \\
Access to finance & 22.1 \\
Skills shortages & 9.4 \\
Accessing business support & 4.3 \\
Other & 4.3 \\
Getting the right technology to produce, store and disseminate ideas/products/services & 3.8 \\
Bureaucratic challenges & 3.8 \\
Customer engagement/involvement & 3.4 \\
Access to digital innovations & 3.4 \\
Getting licences & 3.4 \\
Access to training & 2.1 \\
Finding the right location for your business & 2.1 \\
Taxation & 1.3 \\
Proper place to start the business & 1.3 \\
Property rights & 0.9 \\
Land issues & 0.0
\end{tabular}

Table 3.

Single biggest challenge facing your organisation 
JABES

28,1

40

policymakers to note in ensuring cultural and creative industries grow in the Vietnamese economy.

Although these data are interesting, they need fleshing out further in order to be of more substantive use. Therefore, we used the interviews to probe the survey results further. In doing so, we were able to explore the issues identified in Tables 2 and 3 in much more depth with the data from the qualitative stage of the research. We then undertook an intensive period of coding of the qualitative data through which we identified several emergent issues that policymakers in Vietnam need to begin to address to help fully realise the potential of the creative economies. These were then grouped into four main themes or issues as follows: 1. education and human resource management, 2 . intellectual property rights protection, 3. lack of infrastructure, and 4. freedom of speech.

We used these themes as the core of the model we have constructed: the INCITE model. This is a four-part model of policy development to encourage innovation and creativity in the creative industries within a transitional economy (INCITE). The model is presented in Figure 1. We will discuss the individual building blocks of the model in the subsequent sections.

\section{Developing education and human resources management}

The first priority area that emerged from the data was the need to address pressing concerns in the education sector and in the supply of skills and labour into the creative sector. Education policy needs to be approached from two perspectives - firstly, to increase the skills levels and knowledge of those undertaking creative subjects, and, secondly, to increase awareness of the creative industries amongst those who do not study them directly. To assist with this, policymakers need to include humanistic subjects as well as management, art management, design management and innovation management in the education curriculum. In addition, schools could sign a digital pledge, centred around an artistic discipline, to ensure that the school curriculum brings together art, design, technology and computer science and that young people are able to enjoy greater opportunities to work creatively and with technologies.

Work is needed to close the disconnection between what creative businesses need from graduates and what universities are teaching them. The quote below is representative of the

Figure 1.

INCITE model of policy development for the creative industries in Vietnam

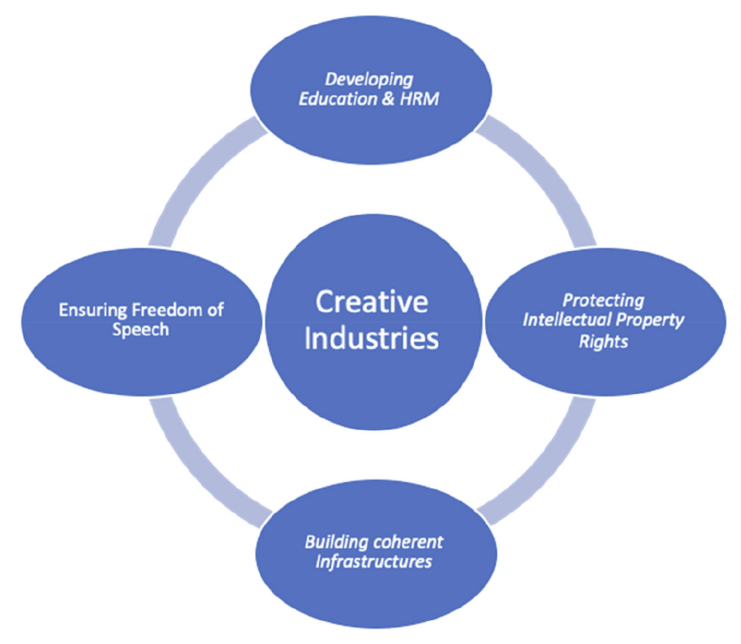


comments respondents gave on the causes of the skills gaps that creative businesses are experiencing - that is, many applicants do not understand the skills sets required to work in the industry.

We lack ... human resources, because few many people really understand. It's really hard to find the right people, to create this space. We also need to build our experience in communicating with government, how to build a plan, strategy, raise funds and attract human resources.

Within the design sub-sectors of the creative economies, a challenge commonly experienced concerns making the industry interested in using design to innovate processes and products, which is consequential in making industry understand how design works. Currently, these two realities are rarely collaborating as there is a lack of understanding of designers' work and its creative processes. Thus, it would be necessary to develop courses aimed at industry (similar to those proposed by the UK Design Council) to increase awareness of the importance of design and the role of designers in organisations, working across environments, businesses and public services - providing design support services and training; delivering partner-funded programmes and running campaigns to raise awareness about the value of design. One possible route to this would be to develop a dialogue that brings together educators, university chancellors, designers and industries to develop university-industry relations and an integrated offer. Some creative hubs have started to offer such courses and creating awareness on the role of design among industries, although they have been contrasted by some of the more traditional academic institutions.

So, a lot of them [industrials] do not know what design is, what is creativity. So, I go from both sides: from business owners and from our student side. There is always a gap between these two groups of people, so I want to make them closer together. In Vietnam, we have more 500,000 small business owners, and I can be sure that not more than 10 have a designer work in their company, so it still depends on design and creativity if they know about creativity and design. If they do not know, they do not value it.

Creativity and design are considered important facets not only of designers' work, but also for creating a vibrant community of a society, which brings people together and makes them feel proud of their job as it contributes to economic development.

There is a huge lack of soft skills, they just seep into work, and time project management, everything like that, we have to either learn by ourselves. If you do not have this kind of skill, you will have difficulty getting a job. For me, it's necessary to have working, soft, life and professional skills.

Related to this is a lack of integration between soft and business skills, including basic accounting, financing and the ability to seek investments, fundraising and marketing their own work. Various spaces are trying to educate public and fellow artists to recognise the role of contemporary art in Vietnam, its crucial importance in creating a contemporary society and pose the question "what is a contemporary society", without becoming commercial products.

In Vietnam, they have the inclination to think contemporary art as a discipline, so they think it's like video art, performance art or something that looks very modern, very new, and they do not think it's a way of thinking.

Moreover, on top of limited public education, there is also a lack of information due to strict censorship in publishing and due to few international newspapers and books, which means libraries in the universities are not up to the required standard. Most ambitious students access such material through the Internet rather than rely on the library provision.
The INCITE model of policy development

(1)


JABES

28,1

\section{Protecting intellectual property rights}

The second policy priority to emerge was the need to address both the current laws relating to Intellectual Property Rights (in terms of strength of law and ensuring enforcement) and the work needed to be done to explain the importance of protecting intellectual property.

This is an issue across the creative industries, within the film and TV sub-section; for example, major distributors and production companies face challenges in terms of IP protection. Downloading pirated copies is not considered bad practice, and many interviewees (enterprises and government) admitted downloading pirated copies of movies.

People do not take responsibility and do not understand the importance of IP, why stopping copying can support cinemas. The problem is not that people do not care; is they do not understand. Thus, policy dialogues and training on the importance of IP is necessary.

As stated, this issue is not restricted to the film industry in Vietnam, and we consistently testify problems related to the lack of understanding of intellectual property. The issue goes beyond the individual makers and artists losing control over their designs. Vietnam's reputation as a reliable and responsible producer of arts and crafts is harmed by a global perception of the amount of cheap copycat goods being produced in the country. This can have a knock-on effect on the reputation of the craft industry as a whole, and ultimately the price the international market is willing to pay for Vietnamese goods.

Therefore, copyright rules need to be strengthened and implemented, balanced with educational purposes leveraging a more creative world by promoting author's rights. If we want authors and creators to continue creating culture and promoting cultural diversity, they must be compensated fairly for the use of their works. The current failure to properly reward creators is limiting creative and cultural industries revenues and holding back their growth and ability to generate job creation.

\section{Building coherent infrastructures for the creative economy}

The third policy priority area we identified comes under the broad banner of infrastructure to support the creative industries. This includes business support, access to finance and tax rules that are suitable for the industry, the regulatory framework and licencing. Vietnamese policymakers need to pay attention to the infrastructure to support the growth of the creative industries. Evidence shows that creative centres are not thriving due to a variety of reasons, including economic reasons and lack of spaces that are open, tolerant, and with high quality life experiences. Policymakers could consider promoting development of spaces that include entertainment, cultural centre and sports centre - places where it is possible to socialise, with cultural and creative activities that are interesting and stimulating. According to evidence from cities internationally (Florida, 2002; Markusen, 2006), creative people well integrated in the ecosystem can start a new business. Creative centres provide an integrated ecosystem where all forms of creativity - artistic and cultural, technological and economic - can take root and flourish (Potts and Cunningham, 2008; Mellander et al., 2013), which is not present yet in Vietnam.

And also the experience of making a masterplan for a hub. If you want to build ecosystems, I think the planning of where hubs sit next to others is very important.

Currently, investments are directed towards creation of districts that resemble theme parks, or are homogeneous or are irrelevant for the creative class. If Vietnam wants to increase the level of creative capital, it should take a more diverse approach to investment in cities and in fostering and preserving local artistic and creative hub centres.

When we focused on the issue of capacity building within the industry, the most common challenges were related to getting licenses and dealing with local officials and regulations. Land use and rental of spaces is the second largest shared concern. Hubs try to support local 
artists and makers to assist with this. One possible way of achieving this could be taking a different approach to rental and market prices for buildings: since they are incubating innovators that have the potential to create companies, they will pay taxes once established and should have favourable treatment when thinking about future returns on investments. This is not only in terms of taxations, but also for returns on the image and development of tourism. One respondent commented:

I think the most important thing is we connect them together. But we're looking for support from government to have good rent space. I think the Vietnamese Government should recognise the roles and importance of creative industries. It should have a good policy for the private sector or local NGOs to develop networks, communities, the environment and ecosystem.

Regarding institutional infrastructure, Vietnam lacks a strong set of institutions to support the creative industries; for example, there is no equivalent body to the UK Design Council. A design centre was opened in Hanoi, in cooperation with Lund University, Vietcraft and the Minister of Trade. It focuses on helping craft-makers develop products exported and to implement sustainable craft-making. The centre is organising workshops and training to 3,000 makers in rural areas. However, activities are impaired by lack of funds. Funds were received also from South Korea to create a design centre over a period of two years, with funding linked to the construction of the centre rather than to a training programme, and several issues emerged during construction that constrained its development. After funding ended, no further steps were taken. Thus, it is important to develop a long-term vision on the use of allocated funds and a strategy to develop businesses-oriented activities, including training.

To address some of these issues, there are a number of steps policymakers in Vietnam could consider that can be grouped under the banner of "infrastructure". The government needs to review and better coordinate the investment in infrastructures with the development of creative economy, urban planning and heritage preservation, but this needs to be done with input from the industry. This can be started with the formation of a "creative innovation system" framework within which strategic priorities can be addressed in a coherent and effective manner and be inclusive of the views and needs of the creative industries. To help with some of the underlying financial issues, the government should consider giving tax relief to creative businesses, opening up opportunities for smaller digital firms and establishing cross-disciplinary research knowledge exchange initiatives and further investment. More international collaborations with leading research centres should be encouraged. Local policymakers require continuous training on the creative economy as there is a gap between the interpretation of the law and the application of the censorship between central government and periphery.

The ways in which the creative economy is taxed and financed is currently one of the obstacles for the development of creative organisations. In the UK and in Europe, cultural productions and consumptions are financed by tax revenues, creating a pseudo-market where cultural goods (in the widest sense of the term, including all sorts of performances and events) generate income through the box-office while being subsidised by the state as they are considered capable of propelling the economy (Styhre, 2013). However, this is not the case in Vietnam, and all the cultural and creative industries are self-reliant (even the opera houses, traditionally supported by the state due to the "Baumol"s cost disease, which includes an increase of the costs associated with the salaries without increasing the productivity): before the financial crisis, they were subsidised by NGOs or foreign corporate sponsorships, but with the recession and the abandonment of the programme, they had learnt to become full market actors.

Making the creative sector part of the economic analysis of Vietnam is indispensable for showcasing its economic and social role in the Vietnamese economy, and we hope this report will be useful for the government to develop policies to support them. To the date, there has

The INCITE model of policy development 
JABES 28,1

been no extensive research conducted in Vietnam, and there is insufficient evidence about the connection between the creative industries, innovation, entrepreneurship and social development in the wider context and economy. Consequently, the policies that have been proposed are momentarily disconnecting these four interconnected domains. As well as impacting on the accounting of creative organisations themselves, the lack of flexibility in the taxation system means that private donations are equally difficult to get:

Because our citizens, we do not have the habit to donate for the arts. And if a business company they want to donate for the arts, they also do not get any discount or no tax refund, anything, for their activities. I know in the States, companies, if they invest for arts they can get the free tax or discounts, but in our country, we do not have this system. That's why the sponsors want to invest only for the reality shows so they can appear their logos on television much more.

Finally, in this area, measures need to be taken to improve the quality and reliability of the data on the creative industries collected by the Statistics Office. Current data sources significantly underestimate the size and scale of the private sector involvement in cultural and creative industries, and this results in an underselling of the sector, both domestically and internationally.

\section{Ensuring freedom of speech}

The final priority policy area that emerged from the data is perhaps the most sensitive and controversial and pertains to freedom of speech. Vietnam's censorship policy is open to local interpretation and has not been amended to take into account the nature of the creative industries. This has led to numerous issues across the subsectors of the creative industries.

Within architecture, for example, the communist aesthetic involves squares and austerity buildings rather than sinuous shapes. Moreover, urban creativity (e.g. graffiti and underground creativity) is not allowed. In other cities, such as Milan, New York and various UK cities, it helped to regenerate deprived areas (Florida, 2002,2014). However, as one respondent from a creative hub commented:

Actually, graffiti is forbidden in Vietnam, and they do not really understand. And also because if you dance or if you do hip-hop, you have to ask for permission from the government and you can ask for permission, but people would just like "Agh!", they do not understand, and they just do not really give you permission for it, which is really hard to actually create more activities and kind of creative industry.

In the film industry, the market's preference is predominantly centred on comedies, romantic, thrillers and action movies - family-friendly, light and easy to follow. They are inspired by popular stories or media sensations well known to the targeted audience. Historical movies are rare, as they need to deal with censorship.

We're not really free, sometimes we want to create, but we're not sure about how censorship will go, so it's quite risky.

In printing, publishing and writing, at the moment, the number of books purchased per year in Vietnam per person is very low (two books), so it is challenging for publishing houses to educate readers and make them engage with content. Because of censorship, writers are not creative.

But we do have young writers, but it is difficult to create outstanding work. I think they are more keen on writing blogs, B-log, or something like that. Writing for children is probably more difficult than for adults.

This leads to a lack of reciprocal trust between the creative communities and the government, with performances, public artistic gatherings and events being policed. One possible solution 
here is for policymakers to investigate international schemes on freedom of speech for the creative industries so that they have a better understanding of how to apply the law without restricting the industry.
The INCITE model of policy development

\section{Conclusions}

The creative industries in Vietnam are rapidly establishing themselves as a vital part of the Vietnamese economy. Developments in Vietnamese creative sectors are at the forefront in shaping a new, enhanced, international reputation for Vietnam in the global economy. The sector presents enormous opportunities for the government, but also presents a series of challenges. This article has begun the process of identifying the policy gaps that exist and developing the INCITE model to support growth and innovation in the industry. Aside from these recommendations, we believe two further steps are critical to growth in these sectors. Firstly, it is imperative that a meaningful policy dialogue takes place between creatives and policymakers to inform and construct policy frameworks fit for the purpose. Secondly, to further improve and strengthen understanding of issues in cultural and creative industries, this research needs to be repeated regularly to track trends as they emerge.

\section{References}

Adler, N.J. (2011), "Leading beautifully: the creative economy and beyond", Journal of Management Inquiry, Vol. 20 No. 3, pp. 208-221.

Cairney, P. (2015), Understanding Public Policy: Theories and Issues, MacMillan Press, London.

Clement, J., Shipilov, A. and Galunic, C. (2018), "Brokerage as a public good: the externalities of network hubs for different formal roles in creative organizations", Administrative Science Quarterly, Vol. 63 No. 2, pp. 251-286.

Davies, R. and Sigthorsson, G. (2013), Introducing the Creative Industries: From Theory to Practice, Sage, London.

DCMS (2001), Creative Industries Mapping Documents, DCMS, HM Government, London.

Denzin, N.K. and Lincoln, Y.S. (2002), The Qualitative Inquiry Reader, Sage, London.

Evans, G. (2009), "Creative cities, creative spaces and urban policy", Urban Studies, Vol. 46 Nos 5/6, pp. 1003-1040.

Ewenstein, B. and Whyte, J. (2007), "Beyond words: aesthetic knowledge and knowing in organizations", Organization Studies, Vol. 28 No. 5, pp. 689-708.

Florida, R. (2014), “The creative class and economic development”, Economic Development Quarterly, SAGE Publications Sage CA, Los Angeles, CA, Vol. 28 No. 3, pp. 196-205.

Florida, R. (2002), The Rise of the Creative Class, Basic Books, New York, NY.

Gasparin, M., Green, W., Lilley, S., Quinn, M., Saren, M. and Schinckus, C. (2020), "Business as unusual:A business model for social innovation”, Journal of Business Research, doi: 10.1016/j. jbusres.2020.01.034 (accessed 6 February 2020).

Howkins, J. (2002), The Creative Economy: How People Make Money from Ideas, Penguin Books, London.

Jones, P., Comfort, D., Eastwood, D. and Hillier, I. (2004), “Creative industries: economic contributions, management challenges and support initiatives”, Management Research News, Vol. 27 Nos 11/ 12, pp. 134-145.

Markusen, A. (2006), "Urban development and the politics of a creative class: evidence from a study of artists", Environment and Planning A, Vol. 38 No. 10, pp. 1921-1940.

Mckinley, A. and Smith, C. (Eds) (2009), Creative Labour: Working in the Creative Industries, Palgrave MacMillan, Basingstoke. 
JABES

28,1

46
McRobbie, A. (2016), "Towards a sociology of fashion micro-enterprises: methods for creative economy research", Sociology, Vol. 50 No. 5, pp. 934-948.

Mellander, C., Florida, R., Asheim, B.T. and Gertler, M.S. (2013), The Creative Class Goes Global, Routledge, London.

O'Brien, D. (2013), Cultural Policy: Management, Value and Modernity in the Creative Industries, Routledge, London.

Peck, J. (2005), "Struggling with the creative class", International Journal of Urban and Regional Research, Vol. 29 No. 4, pp. 740-770.

Peck, J. (2011), “Geographies of policy, from transfer-diffusion to mobility-mutation", Progress in Human Geography, Vol. 35 No. 6, pp. 773-797.

Pink, S. (2013), Doing Visual Ethnography, 3rd ed., Sage, London.

Potts, J. and Cunningham, S. (2008), "Four models and the creative industries", International Journal of Cultural Policy, Vol. 14 No. 3, pp. 233-247.

Pratt, A. (2014), "Creative industries and development: culture development, or the cultures development?", in Jones, C., Lorenzen, M. and Sapsed, J. (Eds), The Oxford Handbook of Creative Industries, Oxford University Press, Oxford.

Quinn, M. and Courtney, R. (2016), "The public sector as an entrepreneur" in Liddle, J. (Eds), Contemporary Issues in Entrepreneurship Research, Emerald, London, Vol. 6.

Styhre, A. (2013), "The economic valuation and commensuration of cultural resources: financing and monitoring the Swedish culture sector", Valuation Studies, Vol. 1 No. 1, pp. 51-81, doi: 10.3384/v.

UNESCO (2015), Creative Economy Outlook 2015, United Nations, New York.

World Bank Group and Ministry of Planning and Investment of Vietnam (2016), Vietnam 2035: Toward Prosperity, Creativity, Equity and Democracy, NW, Washington, DC.

\section{Further Reading}

Cameron, T., Pham, T. and Atherton, J. (2018), "Vietnam today", Vietnam Today - First Report of the Vietnam's Future Digital Economy Project.

Taylor, N.A. (2004), Painters in Hanoi : An Ethnography of Vietnamese Art, University of Hawaii Press, available at: http://www.uhpress.hawaii.edu/p-3164-9780824833558.aspx.

Voss, C., Tsikriktsis, N. and Frohlich, M. (2002), "Case research in operations management", International Journal of Operations \& Production Management, MCB UP, Vol. 22 No. 2, pp. 195-219.

\section{Corresponding author}

Martin Quinn can be contacted at: mrq1@1e.ac.uk

For instructions on how to order reprints of this article, please visit our website:

www.emeraldgrouppublishing.com/licensing/reprints.htm

Or contact us for further details: permissions@emeraldinsight.com 